\title{
Attitudes Of Final Year Dental Students Towards Postgraduate Specialization
}

Fasiha Moin Kazi, Shama Asghar, Syed Adeel Ahmed

\section{ABSTRACT:}

Objective: The aim of this study was to understand the preferences of final year dentistry students in postgraduate specialization and explore the factors which influence them in making decisions regarding their future in pursuing postgraduate studies.

Methodology: A cross-sectional survey was carried out between August 2017- January 2018 at four dental colleges across Karachi, including, three private sector and one public sector institution. A multiple choice, closed-ended questionnaire consisting of 8 statements was prepared and distributed among all the final year BDS students. 225 used and 200 student responses were recorded. Data was analyzed using SPSS version 23 and Chi Square was applied to achieve the results.

Results: $81 \%$ of the respondents were females. $79 \%$ were in the age range of $22-23$ years. $63 \%$ age of students had parents that came from a professional background. $75 \%$ of the total respondents wanted to pursue postgraduate studies. The link between the age of the student, gender and the willingness to pursue postgraduate studies was found to be insignificant whereas with parental profession, it was significant ( $\mathrm{p}$ value $=0.016$ ). $60 \%$ students believed that they had received enough specialty exposure and encouragement from their institutions to be able to decide on their postgraduate plans. The first choice of specialty for $28 \%$ students was Oral Surgery followed by Orthodontics and Endodontics for 22\% respondents. The second choice of specialty for the students was Operative Dentistry for $30 \%$ of the students followed by $17 \%$ who preferred Orthodontics. The rest were divided among the other subjects. $36 \%$ of the students cited their aptitude for a specific field as the most common factor for affecting their decision on specialization. $28 \%$ cited job status/ prospects and financial reasons as the factor most likely to influence their decision on specialization.

Conclusion: According to the study, there was no significant association between the age, gender and the preferences of the student towards postgraduate specialization. However, parental occupation was bound to play a role. The choices of the students as regards specialty selection and influencing factors are varied. As the trend towards postgraduate specialization in dentistry is gaining momentum, it is imperative to research this area more for better planning and allowing students to make informed decisions.

Key words: attitudes, postgraduate, preferences, specialization, Karachi, Pakistan

\section{INTRODUCTION:}

Specialization in dentistry is a relatively new concept in Pakistan with dentistry being considered a specialized subject per se by the vast majority ${ }^{1}$. However with the increase in the number of dentists across the country due to the mushrooming of dental colleges ${ }^{2}$ in the last two decades, the need for specialists in the field has never been greater. To date, there are 19539 general dental practitioners and 1867 specialist dental practitioners registered by the Pakistan Medical and Dental Council in Pakistan ${ }^{3}$. There are 506

$\begin{array}{ll}\text { Fasiha Moin Kazi } & \text { I } \\ \text { Registrar, Operative Dentistry } & \text { I } \\ \text { Bahria University Medical and Dental College } & \text { I } \\ \text { Shama Asghar } & \text { I } \\ \text { HOD \& Associate Professor } \\ \text { Operative Dentistry } \\ \text { Bahria University Medical and Dental College } \\ \text { Email:shama.asghar24@gmail.com } \\ \text { Syed Adeel Ahmed } \\ \text { Registrar, Operative Dentistry } \\ \text { Bahria University Medical and Dental College } \\ \text { Received: 04-09-2018 } \\ \text { Accepted: 26-09-2018 } \\ \text { I }\end{array}$

dental specialists registered in $\operatorname{Sindh}^{3}$. However, there is very limited data available about the preferences of the graduates and budding specialists ${ }^{4}$. This study is an attempt to understand the factors which lead students towards specialization as well as the factors which discourage them from further studying. As the available local literature on the subject appears to be scarce and almost non-existent it is hoped that this study would help understand and record the trends in postgraduate specialization in dentistry and that this would encourage others to research further into this important arena. As data collection is the basic step towards better planning, further research would help in better planning and resource allocation for our postgraduate programs.

A study of international trends on this subject reveals that each country may have its own set of preferences for specialization and that this may be dictated by the cultural norms as well ${ }^{5}$. For instance, in Japan, the percentage of students favoring specialization has been $38.8 \%$ as compared to the UK where its $83 \%{ }^{5}$. With the traditional Japanese business and societal model more focused on generalization, this seems to be a likely result ${ }^{6}$. It is also speculated that the inheritance of private dental set-ups by young second 
generation Japanese dentists also acts as a deterrent in pursuing further studies ${ }^{5}$. Similarly in Iran, the majority of the students planned to enter private practice; fewer intended to pursue specialty education $\operatorname{abroad}^{7}$. The most popular reasons for these students' choice of dentistry as a career were a general interest in medicine and a desire to enter a prestigious profession with high social status. Most of the female students planned to work in a group practice environment such as a clinic rather than a solo practice ${ }^{7}$ and single students showed greater enthusiasm than married ones for pursuing further studies abroad after graduation ${ }^{7}$.

In the UK, final year students place Orthodontics as the most preferred subject for specialization followed by Restorative Dentistry ${ }^{5,8}$. In Sweden, Oral Surgery is the preferred field ${ }^{5,9}$. Thai students are also most interested in Oral surgery whereas students in Canada prefer Orthodontics 5, 10 . A study carried out by the Annual American Dental Education Association from 1995-2004 in all the dental schools across the USA places Orthodontics as the most preferred area for specialization by students followed by Oral and Maxillofacial Surgery and Pediatric Dentistry ${ }^{5,11}$. Another study carried out at a dental school in the US emphasizes the role of gender in the decision for specialization. It states that male dental students are more likely to opt for Oral Surgery while female students prefer Pediatric Dentistry ${ }^{5,12}$.

\section{MATERIALS AND METHODS:}

A cross-sectional survey was carried out from August 2017 to January 2018 using a closed-ended questionnaire which was provided to students of final year BDS. Students from Bahria University Medical and Dental College, Baqai University Dental College, Fatima Jinnah Medical and Dental College and Dow University of Health Sciences participated in the study. Sample size was estimated from openepi.com software. The conditions were $95 \%$ confidence interval, $5 \%$ margin of error. Population size was estimated to be 525 (secondary source of information collected form selected colleges) at a prevalence rate of $50 \%$. The required sample size was drawn to be 223. Ethical approval was obtained from the Ethical Review Committee at Bahria University Medical and Dental College; ERC no. 06/2018. Informed consent was obtained from all the participants.

In questionnaire, participants were categorized on the basis of age, gender and parental occupation. The purpose was to find if there was a potential link between these characteristics and the preferences of the subjects towards specialization. Students were asked to identify their first and second choice of specializing subject in dentistry. They were then asked about the factors which might influence their decision in a positive as well as negative manner. The role of institutional encouragement and/or guidance was also explored. As identified in the literature review, the positive influencing factors included financial prospects, professional status, aptitude for a particular specialty and family and friend's expectations. Distracting or discouraging factors included the length of time needed to complete postgraduate studies, cost or expense of the course, competition in postgraduate studies, further studying and the lack of any particular need to specialize.

SPSS 23 was used for compilation of the data. Frequencies were calculated for all the categories as well as the factors. Chi Square was applied and a p -value of less than 0.05 was considered significant.

\section{RESULTS:}

A total of 225 questionnaires $(n=225)$ were completed by final year BDS students. Seven questionnaires were not completely filled by students and so were excluded from the study, making $\mathrm{n}=218$.

$81 \%$ of the respondents were females. $19 \%$ were males. $79 \%$ of the students were aged $20-23$ years. $13 \%$ of the students were aged $20-22$ years. $4 \%$ of the students were aged $24-25$ years. $4 \%$ of the students were aged $26+$ years. $63 \%$ of respondents had parents with a professional background. $20 \%$ parents were from a managerial/corporate background. $10 \%$ parents were skilled (Technical). $6 \%$ parents were skilled (non-technical). $2 \%$ were of various other backgrounds. $75 \%$ of respondents were interested in pursuing a specialist career; $9 \%$ of respondents did not want to study further, $16 \%$ students were undecided about their future plans.

Relationship between age and post -graduation: The relation between the age of the respondents and their willingness to get a postgraduate education was not significant as a p-value of 0.418 was achieved. $59.6 \%$ of the respondents belonging to the 22-23years age group wanted to pursue a postgraduate education.

Relationship between gender and post -graduation: The gender of the respondents did not have a significant influence on the decision to specialize as p-value was 0.48 (Table 3 ). $76 \%$ of the total females wanted to pursue postgraduate studies as opposed to $71 \%$ of the total males. (Table 1 )

Relationship between parental occupation and postgraduation: Parental occupation had a significant influence on the decision to specialize as $p$ value was found to be 0.016 (Table 2). $82 \%$ of students who had parents from a professional background showed interest in pursuing specialization.

Institutional support: $60 \%$ students believed that they had received enough specialty exposure and encouragement from their institutions to be able to decide on their postgraduate plans. 40\% students believed otherwise (Fig.1).

First choice of specialty: $28 \%$ respondents chose Oral Surgery as their first choice of specialty for postgraduate studies. 22\% chose Orthodontics and Endodontics. Pediatric Dentistry was opted by $11.5 \%$. Operative Dentistry was 


\begin{tabular}{|l|r|r|r|r|}
\hline \multirow{2}{*}{ Gender } & \multicolumn{3}{|c|}{$\begin{array}{c}\text { Do you intend to pursue a } \\
\text { specialist career? }\end{array}$} & \multirow{2}{*}{ Total } \\
\cline { 2 - 4 } & Yes & No & $\begin{array}{c}\text { I have not } \\
\text { decided yet }\end{array}$ & \\
\hline \multirow{2}{*}{ Male } & 30 & 3 & 9 & 42 \\
\hline Female & $71.4 \%$ & $7.1 \%$ & $21.4 \%$ & $100.0 \%$ \\
\hline & $76.1 \%$ & $9.7 \%$ & $14.2 \%$ & 176 \\
\hline Total & 164 & 20 & 34 & 218 \\
\hline & $75.2 \%$ & $9.2 \%$ & $15.6 \%$ & $100.0 \%$ \\
\hline
\end{tabular}

Table 1: Gender-wise distribution of respondents intending to pursue post-graduation

\begin{tabular}{|l|c|c|c|c|}
\hline \multirow{2}{*}{} & \multicolumn{3}{|c|}{$\begin{array}{c}\text { Do you intend to pursue a } \\
\text { specialist career? }\end{array}$} \\
\cline { 2 - 4 } & Yes & No & $\begin{array}{l}\text { I have not } \\
\text { decided yet }\end{array}$ & \multirow{2}{*}{ Total } \\
\hline Professional & $112,(81.8 \%)$ & $13,(9.5 \%)$ & $12,(8.8 \%)$ & 137 \\
\hline Managerial/Corporate & $26,(59.1 \%)$ & $3,(6.8 \%)$ & $15,(34.1 \%)$ & 44 \\
\hline Skilled (technical) & $16,(76.2 \%)$ & $2,(9.5 \%)$ & $3,(14.3 \%)$ & 21 \\
\hline Skilled (manual) & $8,(66.7 \%)$ & $1,(8.3 \%)$ & $3,(25.0 \%)$ & 12 \\
\hline Others & $2,(50.0 \%)$ & $1,(25.0 \%)$ & $1,(25.0 \%)$ & 4 \\
\hline Total & $164,(75.2 \%)$ & $20,(9.2 \%)$ & $34,(15.6 \%)$ & 218 \\
\hline
\end{tabular}

Table 2: Relationship between the parental occupation and the desire of the respondents to pursue post-graduation

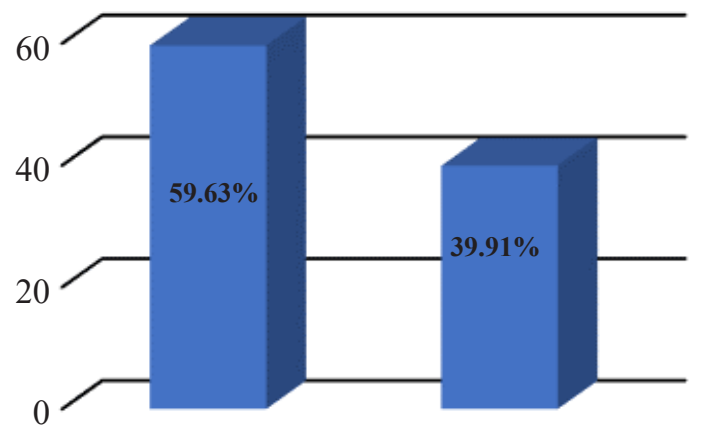

Fig. 1 : Perceived institutional support of the respondents willing to pursue postgraduation.

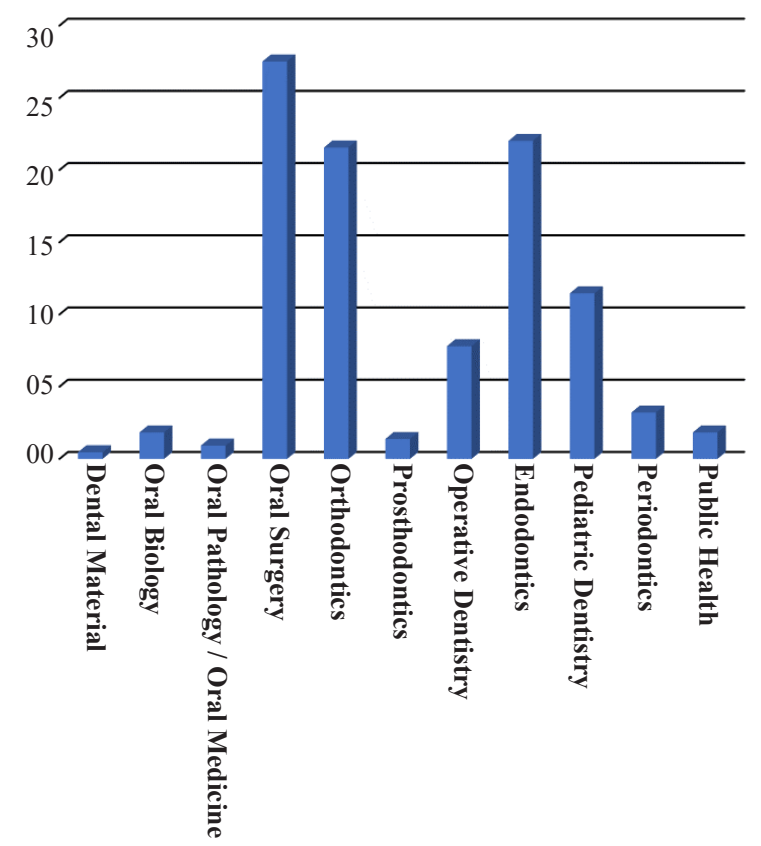

Fig. 2: First choice of specialty for post-graduation as decided by the total number of respondents. 
chosen by $7.8 \%$. Periodontics was opted by $3.2 \% .2 .3 \%$ chose Oral Biology. Public Health was opted by $1.8 \%$. Prosthodontics was chosen by $1.4 \%$. $0.9 \%$ chose Oral Pathology/ Oral Medicine. 0.5\% of students chose Dental Materials (Fig. 2). 29\% of males wanted to choose Oral surgery as their first choice of specialty followed by $26 \%$ who wanted to opt for Orthodontics. $27 \%$ of females wanted to choose oral surgery as their first choice of specialty followed by $25 \%$ who wanted to choose Endodontics.

Second choice of specialty: $30 \%$ of students wanted to opt for Operative Dentistry as their second choice for specialization, followed by $17 \%$ who preferred Orthodontics. $12 \%$ opted for Endodontics. 11\% chose Oral Medicine /Oral Pathology. Prosthodontics was chosen by $6.9 \%$. Dental Materials, Pediatric Dentistry and Public Health were selected by $2.3 \%$, Oral Biology was chosen by $0.9 \%$, Pediatric Dentistry was chosen by $2.3 \%$. Thirty one percent males opted for Operative Dentistry as their second choice of specialty whereas $19 \%$ opted for orthodontics. $30 \%$ females opted for orthodontics as their second choice of specialty whereas $17 \%$ opted for Orthodontics.

Influencing factors on post-graduation decision: $36 \%$ of the students cited their aptitude for a specific field as the most common factor for affecting their decision on specialization. $28 \%$ cited job status/prospects and financial reasons as the factor most likely to influence their decision on specialization. Family and friend's expectations were cited by $12.4 \%$. Further studying was opted by $12.8 \%$. Professional status was cited by $6.9 \%$.Dearth of specialists in the country was cited by $3.2 \%$.

Discouraging factors for postgraduate studies: $40.4 \%$ students cited the length of time needed for postgraduate studies as the most likely reason to get discouraged from specialization. $24 \%$ of students chose the cost of specialization and the expenditure incurred as the reason most likely to discourage them from specialization. Further studying was cited by $16.5 \%$. Too much competition was cited by $14.2 \%$. $5 \%$ students felt they did not need to specialize.

\section{DISCUSSION:}

The majority of the participants of the study $(80 \%)$ were females and belonged to the 22-23 years age bracket. It is a fact that an increasing number of female students are opting for medicine and allied sciences in Pakistan ${ }^{13}$. The reasons for this are manifold. However, this makes it difficult in this study to establish any true association between gender and the predilection for postgraduate studies as the majority of respondents are already females. If we consider the total respondents, around $75 \%$ of them showed an interest in pursuing postgraduate studies which is encouraging. What remains to be seen is how much of this interest translates into actually undertaking specialization and what are the factors that hinder the process; this can be the subject of further research in this area.
The fact that $60 \%$ of the students suggested that they had received institutional exposure or guidance regarding their post-graduation suggests better awareness, counseling and mentoring are being undertaken at institutional level for students to make informed decisions about their future. This is an encouraging trend for developing countries like Pakistan. Around $82 \%$ of students came from a background of professional parents and the association between parental occupation and an interest in postgraduate studies was established ${ }^{14}$. A possible reason for this association could be the greater importance to education and studies imposed by parents who had achieved a certain level and awareness of education themselves.

On the matter of deciding the first choice for specialization, opinion appeared divided and there was no particular swing towards any one field or specialty. However, most of the students opted for clinical science subjects like Oral surgery and Orthodontics rather than basic science subjects. This may be attributed to the fact that psychomotor skills and clinical procedures constitute an integral part of dentistry ${ }^{15}$ and by the time a student is done with final year, it is difficult to imagine a professional dental surgeon who is not involved in practical work. Also, these subjects offer better remuneration as compared to the other options available ${ }^{16}$. For the second choice $30 \%$ of students opted for Operative Dentistry with the rest being divided among other specialties. The most common influencing factor were an aptitude for the specialty $(36 \%)$ and job status/prospects and financial reasons $(28.4 \%)$.

The fact that students cited the length of time needed to complete postgraduate studies as the most discouraging factor followed by the expenditure incurred is also selfexplanatory. As most of the respondents were females, it can be understood that the postgraduate period is also the most demanding time on the domestic front. Multiple factors like raising a family and bearing their financial and other responsibilities can affect the decision making process. It is imperative that appropriate measures are taken on the national level to facilitate the female work force in dentistry in pursuing their further studies. The dearth of adequate child-care centers and stipend/financing for post-graduation studies can discourage a good number of talented professionals from progressing in their careers ${ }^{17}$. From the point of view of male doctors, the remuneration factor seems more important as the additional cost of studies has to be weighed with the financial responsibilities of the family ${ }^{17,18}$. Steps need to be taken in this regard to remove all hindrances towards pursuing a postgraduate specialization. A review of the local and regional literature related to the study shows that there is a dearth of available data on the subject. More research needs to be conducted in this important domain. The responses received show that the concerns of the students and their preferences need to be considered when planning out postgraduate programs ${ }^{19,20}$. More research in this field 
can help in good planning and an improvement in the standard of care of our health care system ${ }^{21,22,23}$.

\section{CONCLUSION:}

This study shows that a large number of undergraduates had an intention to specialize, with Oral Surgery, Orthodontics and Endodontic being the most popular planned subjects, although many were still undecided at this stage. The parental occupation of the student play an important role in the eventual preferences but the choices are varied and as the students' value time and finances at this important juncture in their lives, adequate and well-tailored programs need to be planned to suit the needs of our students and to facilitate them in becoming better clinicians and academicians. More data needs to be collected, however, to allow informed decision-making for the students as well as the institutions.

\section{REFERENCES:}

1. Halawany, H. Career Motivations, Perceptions of the Future of Dentistry and Preferred Dental Specialties among Saudi Dental Students. The Open Dentistry Journal 2014; 8(1): 129135.

2. Khan F. If Dental Colleges were Dentist-Producing Factories. Journal of The Pakistan Dental Association. 2017; 26(3):99100.

3. Recognized Dental Colleges in Pakistan [Internet]. Pmdc.org.pk. 2018 http://pmdc.org.pk/Recognizeddentalcollegesinpakistan/tabid/167

4. Puryer J, Kostova V, Kouznetsova A. Final-Year Dental Undergraduate Attitudes towards Specialisation. Dentistry Journal 2016; 26(4): 2-10 doi:10.3390/dj4030026

5. Baharvand M, Moghaddam E, Pouretemad H, Alavi K. Attitudes of Iranian Dental Students Toward Their Future Careers: An Exploratory Study [Internet]. Journal of Dental Education. 2018 [cited 30 July 2018]. Available from: http://www.jdentaled.org/content/75/11/1489.

6. Karibe H, Kawakami T, Suzuki A, Warita S, Ogata K, Aoyagi $\mathrm{K}$ et al. Career choice and attitudes towards dental education amongst dental students in Japan and Sweden. European Journal of Dental Education 2009; 13(2):80-86.

7. Karibe H, Suzuki A, Sekimoto T et al., Cross-Cultural Comparison of the Attitudes of Dental Students in Three Countries, Journal of Dental Education November 2007; 71 (11): 1457-1466.

8. Okwuje I, Anderson E and Valachovic R W, Annual ADEA Survey of Dental School Seniors: 2008 Graduating Class, Journal of Dental Education 2009; 73 (8): 1009-32.

9. Scarbecz M and Ross J, The Relationship Between Gender and Postgraduate Aspirations Among First- and Fourth-Year Students at Public Dental Schools: A Longitudinal Analysis. Journal of Dental Education 2007; 71 (6) 797-809.
10. Zia-Ul-Ain S, Adnan S, Khaliq H, Irfan M. A cross sectional study on the choices of female medical students in selection of their future specialties, JPMI. 2014; 30(3).

11. Rehman A, Rehman T, Shaikh MA, Pakistani medical students' specialty preference and the influencing factors .JPMA 2011; 61:713-16.

12. Oladele K. Ogunsola, Kazeem A. Osuolale, Akintayo O. Parental and Related Factors Affecting Students' Academic Achievement in Oyo State, Nigeria. International Scholarly and Scientific Research \& Innovation 2014; 8(9); 3137-44

13. Khalaf ME, Alkhubaizi Q, Alomari QD. Layered Base Plate Blocks and Operative Dentistry Skills. J Contemp Dent Pract 2018; 19(5):554-559.

14. Nazarova E, Peele M M , Fifield J, . U.S. Dental Specialty Residents' Expectations and Anticipated Benefits of Academic Employment. Journal of Dental Education 2016, 80 (10): 1196-1204

15. Kfouri M, Moysés S. T, Gabardo M C, Moysés S J, Gender differences in dental students' professional expectations and attitudes: a qualitative study, British Dental Journal 2017; 223: 441-45

16. Tahir S, Bashir A, Rafique A, Khan J. The barriers which prevent female dentists from pursuing their career in Pakistani culture. Pakistan Oral \& Dental Journal 2017; 37(3):477-82.

17. Grytten J. Payment systems and incentives in dentistry. Community Dent Oral Epidemiol 2017; 45: 1-11.

18. Gadit AA. Professional competence assessment: is it a wakeup call for Pakistan? J Pak Med Assoc. 2010; 60: 965-66.

19. Jawaid SA. Seminar on Dental Education during AEME Conference. [Online] 2017. [Cited 2017 Jun 14]. Available from: http:/ /www.pulsepakistan. com/index. Php/ main-newsapr1-17/2025-we-have-no-future-direction-vision-and-strategyin dental-education-ahsan-sethi.

20. Ali K, Raja M, Watson G, Coombes L, Heffernan E. The dental school learning milieu: students' perceptions at five academic dental institutions in Pakistan. J Dent Educ. 2012; 76:487-94.

21. Sethi A, Khan A, Is the dental clinical learning environment suitable? A survey of Khyber Pakhtunkhwa, Pakistan. Journal of the Pakistan Medical Association 2018; 68: 359-61

22. Williams J C, Clements S, Making time for what's important: what elements should we value when planning practice-based professional training? British Dental Journal 2016; 221: 109111

23. Shin J H, Kinnunen T H, Zarchy, Da Silva J D et al, Factors Influencing Dental Students' Specialty Choice: A Survey of Ten Graduating Classes at One Institution, Journal of Dental Education 2015, 79 (4) 369-377; 